\title{
Educação formal, não-formal e Hip Hop Contextos e desafios educacionais no Brasil e Cabo Verde
}

Vitor Mafra

\section{Resumo:}

O modelo escolar moderno que foi universalizado durante o século $\mathrm{XX}$, mostrou-se incapacitado de responder todas as demandas sociais que lhe foram impostas. Dessa forma, durante a segunda metade deste século a crise do sistema de ensino formal deu abertura a diversos debates sobre questões que permeiam a ação de educar, como os espaços, os atores e porque não sobre próprio conceito: o que é educar? Sendo assim, neste artigo trago reflexões sobre a educação formal, dentre outras formas, analisando o contexto da educação no Brasil e em Cabo Verde, para compreender de que maneira determinados atores sociais, como os rappers, podem contribuir para a construção de uma educação emancipadora.

\begin{abstract}
:
The modern school model that was universalized during the twentieth century proved incapable of responding to all the social demands imposed on it. Thus, during the second half of this century the crisis of the formal education system opened up several debates on issues that permeate the action of educating, such as spaces, actors and why not on its own concept: what is it to educate? Thus, in this article I bring reflections on formal education, among other forms, analyzing the context of education in Brazil and Cape Verde, to understand how certain social actors, such as rappers, can contribute to the construction of an emancipatory education.
\end{abstract}

\section{Introdução}

A educação é essencial para conceber a vida humana. De forma genérica, somos educados para suprir as necessidades do corpo (alimentação, locomoção, entre outras) e da mente (comunicação, memória, entre outros), pois é através delas que conseguirmos conviver de forma 
orgânica em sociedade. Educar, então, é não somente uma ação que nos permite desenvolver as atividades físicas e intelectuais, mas também um importante meio para regular a sociedade, sendo um transmissor direto de cultura, pois prescreve uma maneira de pensar e agir, criando assim normas, costumes, sentimentos morais e estéticos em comum.

A concepção de educação elaborada pelo intelectual iluminista Immanuel Kant influenciou muito o modelo escolar criado na modernidade e que se reproduz até hoje. Segundo o filósofo, o homem se funde através da educação e ela o que o faz, tendo a disciplina e autodomínio como elementos principais para uma boa aprendizagem. É a partir de referenciais como estes que se funda o modelo de educação formal, rígido, disciplinado, conteudista e repleto de normas aplicado até hoje nas instituições escolares de ensino. Entretanto, a partir da segunda metade do século XX, novas formas de educação começam a serem debatidas.

Os sistemas educacionais começam a se demostrar obsoletos e de certa forma ineficientes. Segundo Trilla (1996), a expressão educação nãoformal surge da crítica ao sistema formalizado de ensino não somente no campo pedagógico, mas também por diversos setores da sociedade como o da área da saúde, serviço social, da cultura, entre outros. Movimentos sociais e ONGs também demonstravam a sua insatisfação, pois percebiam “(...) a escola e a família como impossibilitados de responder a todas as demandas sociais que lhe são impostas, delegadas e desejadas" (GARCIA, 2008, p.1). Sendo assim, em um primeiro momento, a educação não-formal surge como campo conceitual de contraponto a educação formal.

A partir da década de sessenta, o termo desponta e começa a aparecer em diversos estudos sobre essa a crise da educação. No mundo todo, e como veremos mais adiante no contexto brasileiro e cabo-verdiano, começa-se a debater sobre a impossibilidade da escola responsabilizar-se pela educação de forma ampla e genérica. As instituições formais de ensino além de estarem distantes dos contextos sociais dos alunos e não conseguirem democratizar o acesso ao saber, direito constitucional prescrito em diversos países, não se constatou um perfil de "transformação social" que se 
esperava. Ou seja, não conseguiu estender a educação aos segmentos marginalizados e mais carentes da sociedade de forma a proporcionar, de fato, mudanças concretas e avanços referentes à desigualdade social. Dessa forma, novas maneiras de educação, complementares ou não à educação formal, começaram a serem debatidas nesses espaços, e determinados atores sociais, como rappers, começam a ser visto para além de artistas; mas como educadores sociais.

Como foi visto anteriormente, a educação não-formal começa a se popularizar na década de sessenta. Segundo Trilla (1996), em 1967 com a Internacional Conference on World Crisis in Education, realizado em Williamsburg - Virgínia (Estados Unidos) é que, através da elaboração de um documento, a educação não-formal é oficializada como campo do setor educacional. Outro documento importante para firmar a educação nãoformal como parte do campo educacional foi a Declaração Mundial sobre Educação para Todos promovido pela Unesco no dia 9 de março de 1990 na Tailândia através de uma conferência mundial. Esse documento foi importante, por trazer as experiências de diversas ONGs com programas educacionais que visam transcender a égide formal.

Todavia, antes de prosseguir, vale ressaltar que os desafios da educação não devem ser analisados de maneira a separar o campo da educação formal e não-formal, visto que eles “(...) conversam, se complementam, se alimentam e se constituem um ao outro, mas com uma identidade própria. A fronteira entre eles não é estática, se modifica de acordo com seus fazeres" (GARCIA, 2008, p.1). Tanto que muitos autores e pesquisadores, como em Ghanem (2008), retratam a necessidade de avaliar o sistema educacional supondo outras formas para além da educação formal.

Mesmo que sejam ainda pouco incluídas no sistema escolar convencional, elas - educação não-formal, popular, social, entre outras estão em constante expansão, pois não se restringem ao ambiente escolar. Não obstante e se atendo ao campo da educação não-formal, os processos educativos podem ocorrer tanto por intermédio de organizações sociais, movimentos não-governamentais (ONGs) e outras entidades filantrópicas, 
quanto por atores sociais engajados que procuram, através de suas oficinas (artesanais, culturais, esportivas e/ou recreativas) por exemplo, aproveitar as suas experiências individuais e compartilha-las para educar. Sendo assim, para estudar a educação não-formal, é preciso compreender que trata-se de um campo em constante (re)construção, pois devido a elevada flexibilidade dos conteúdos, diversidade dos espaços e dos métodos de ensinagem e aprendizagem, não há conceitos prévios que possam defini-la conceitualmente. Então de que maneira seria possível fazer um estudo que caminhe para compreender as problemáticas, bem como fomentar soluções práticas?

Deste modo, o objetivo central deste artigo é, a partir do levantamento bibliográfico, analise documental e de minha experiência empírica, contribuir a discussão analisando o contexto da educação no Brasil e em Cabo Verde ${ }^{1}$, e compreender de que maneira determinados atores sociais, como os rappers, podem mostrar caminhos à crise e obsolescência do modelo de educação formal, bem como contribuir para a construção de uma educação emancipadora.

\section{Educação no contexto brasileiro e cabo-verdiano}

Como foi visto no tópico anterior, as primeiras discussões sobre a educação não-formal e as tentativas de compreendê-la como setor do campo educacional, aconteceram nos anos sessenta devido a crise global do sistema formal de educação. E foi durante esta mesma década e no início dos anos setenta do século XX, que o pedagogo brasileiro Paulo Freire trouxe uma nova perspectiva ao sistema de ensino, tendo grande influencia tanto no Brasil quanto em Cabo Verde.

\footnotetext{
${ }^{1}$ No segundo semestre de 2017 estive em Praia (Cabo Verde) em missão de estudos a partir do projeto Brasil e Cabo Verde - limites e possibilidades de pesquisa entre países sob a perspectiva do multiculturalismo, multilinguismo e mundo digital: web indígena $e$ afrodescendente, na biblioteca digital e educação inclusiva, do Programa de PróMobilidade Internacional CAPES/AULP (Edital 33/2012). Fato que proporcionou analisar empiricamente o sistema de educação formal no país, bem com a educação nãoformal, principalmente a partir da atuação dos cantores de rap nesse campo.
} 
Mais conhecido na época como o método Paulo Freire, o autor procurou nomeá-lo como educação popular, pois visava ressaltar que essa nova pedagogia foi desenvolvida para com o povo. Ou seja, visa educar, principalmente as classes desprotegidas e marginalizadas através de uma pedagogia inclusiva, na qual os saberes das comunidades servem, a partir das suas experiências e vivências cotidianas, como matéria prima para o ensino. Sendo assim, a educação busca suscitar a conscientização, o empoderamento e emancipação social, cultural e política da classe trabalhadora. E foi esse movimento pedagógico, e porque não político, que influenciou muitos países da América Latina e alguns africanos recémindependentes, como o exemplo de Cabo Verde.

A proclamação de independência de Cabo Verde só ocorreu no dia 5 de Julho de 1975. Naquele período, de acordo com o documento Educação Popular - O caso de Cabo Verde coordenado pelo Gabinete de apoio às ONG e pelo Secretariado Executivo da Plataforma das ONG, mais de $60 \%$ da população do país era analfabeta. Por isso que o PAIGC, partido panafricanista de orientação comunista que liderou o processo revolucionário de independência, promoveu um elevado investimento na educação pública, e até hoje a educação é uma das prioridades dos governos ${ }^{2}$. Todavia, todo esse investimento não teve os efeitos esperados:

Os resultados obtidos ficam muito aquém das expectativas, designadamente: muitos jovens permanecem desenraizados, desempregados e alienados, sem uma preparação adulta e autoconfiante (CORREIA, 2007, p.38).

De acordo com a Lei de Bases de Bases do Sistema Educativo de Cabo Verde (Lei n. ${ }^{o}$ 103/ III/90, de 29 de Dezembro, alterada pela Lei 113/V/99, de 18 de Outubro), o sistema educativo de Cabo Verde contém

\footnotetext{
${ }^{2}$ Através dos dados retratados no documento Educação Popular - O Caso de Cabo Verde (2008), houve um crescimento contínuo de investimento na educação a partir do PIB do país: 9,4\% em 1980 (4,4\% do PIB) ; 10,0\% em 1985 (5,6\% do PIB); 13,0\% em 1990 (5.9\% do PIB); 20,2\% em 2000 (7,1\% do PIB); e 23\% em 2005 (7,1\% do PIB).
} 
como subsistemas: educação pré-escolar, educação escolar e educação extra-escolar. É nesta última que abrange a educação popular e não-formal.

Em Cabo Verde, a educação não-formal está bastante vinculada à aquisição de conhecimentos para adquirir melhor empregabilidade, (...) adaptação à sociedade da informação e de conhecimentos, a aquisição dos bens culturais, o exercício de uma cidadania activa e a aprendizagem permanente" (GABINETE DE APOIO ÀS ONGS E SECRETARIADO EXECUTIVO DA PLATAFORMA DAS ONG, 2008, p.28). Entretanto, devido a grande influencia da pedagogia freireana, a educação não-formal no país tem grande influencia da educação popular ${ }^{3}$ no início de seu desenvolvimento. É importante salientar que o número de ONGs no país aumentou vertiginosamente a partir da década de oitenta e isso trouxe mudanças ${ }^{4}$. Da mesma forma que as ONGs, junto a outras organizações comunitárias, hoje são as principais responsáveis pela educação popular no país, possibilitou que a educação não-formal perdesse também a sua influencia do método Paulo Freire.

Fazendo um parêntese e aproveitando Gohn (2010), quando se refere ao contexto brasileiro (que passou por um processo semelhante), a autora salienta que nem toda educação formal é popular e exemplifica justamente o caso das ONGs e do terceiro setor, cujas ações socioeducativas não traduzem necessariamente em processos que promovem a autonomia e o empoderamento dos sujeitos envolvidos. Da mesma forma que ações da educação não-formal podem ocorrer através de ONGs, movimentos sociais, instituições públicas de ensino, organizações comunitárias, entre outros, a diversidade também está presente nos seus objetivos e é necessário saber diferenciá-los. Existem aquelas ações, de cunho assistencial e pontual, que

\footnotetext{
${ }^{3}$ A Federação Caboverdiana da Juventude (FCJ), por exemplo, promoveu em parceria com a Direção Geral da Juventude (DGJ) e as Nações Unidas (NU), um curso de formação em educação não-formal. Com o objetivo de “(...)capacitar jovens para transformar a realidade e intervir nas suas comunidades a nível das diferentes áreas sociais, recreativas, culturais, desportivas, ambientais e de saúde, como forma de possibilitar as boas práticas sociais". Disponível em <https://www.facebook.com/FCJ.CV/posts/384991618258698>. Acesso em: 26 de março de 2019.

${ }^{4}$ De acordo com o documento Educação Popular - O Caso de Cabo Verde (2008), o número de ONGs em Cabo Verde era de: 8 em 1985, 13 em 1990, 63 em 2000, e hoje são aproximadamente 600 que estão atuando.
} 
não abalam as estruturas sociais, ou seja, que promovem a manutenção do status quo ${ }^{5}$. Todavia, existem aquelas que vão além do assistencialismo. Com amplitude maior, os movimentos sociais, por exemplo, procuram através da arte, da manifestação política e de outros meios, proporcionar o engajamento e a autonomia ao povo para conquistarem os seus direitos sociais.

No caso brasileiro, como foi visto, a discussão sobre educação nãoformal enquanto um setor do campo educacional também começou na década de sessenta do século XX. Todavia, Garcia (2008) ressalta que antes de haver o termo, as atividades dessa área já eram desenvolvidas e identificadas com outras terminologias: educação complementar, educação alternativa, educação fora da escola, entre outras.

Assim como em Cabo Verde, o método Paulo Freire teve grande influência para as pedagogias extra-escolares. A mesma partia do pressuposto que a escola exclui a classe trabalhadora do direito ao saber, por isso Paulo Freire foi uma grande ativista na luta pela alfabetização, atuando principalmente em áreas rurais e para adultos. Isso ajuda e compreender, por exemplo, porque a educação não-formal, nas décadas de setenta e oitenta, esteve fortemente ligada a alfabetização de adultos fora dos ambientes escolares. Pois bem, vale ressaltar também que existem outros fatores importantes que influenciaram a ascensão da educação não-formal.

Como foi visto, a década de sessenta foi um período de amplo debate sobre a crise da educação formal. A globalização, a urbanização e os novos paradigmas do mercado mundial suscitam questões importantes para compreender as críticas aferidas à obsolescência do sistema formal de ensino e outros espaços tradicionais de educação. Alguns dos pontos que trazem esses questionamentos são a:

\footnotetext{
${ }^{5}$ A “(...) educação não-formal, quando consideramos os projetos voltados para crianças e jovens oriundos das camadas pobres da sociedade, ainda é concebida, por diferentes setores, inclusive o educacional, como oferecedora de atividades para passar o tempo, brincar, ocupar a cabeça com coisas mais interessantes, para "tirá-los das ruas", ou seja, atividades vistas como de menor importância e que não têm o compromisso de contribuir para a construção do homem social na sua totalidade, considerando apenas que essa contribuição se dá de maneira casual”(GARCIA, 2008, p.12).
} 
- Menor influencia a educação familiar na formação dos indivíduos, devido principalmente demandas do mercado de trabalho que contribuem para reorganização da estrutura familiar.

- Violência Urbana. Os espaços públicos (ruas, praças, parques, etc) são vistos cada vez mais como espaços perigosos para as crianças, sendo assim, muitos pais optam, devido a segurança, em ocupar o tempo livre de seus filhos com atividades extra-escolares.

- Diminuição do quadro familiar. Isso dificultou o papel da educação familiar (informal) na formação dos cidadãos.

- Dificuldade das indústrias e do mercado profissional de encontrar profissionais (formais) habilitados em suprir as suas demandas.

Enfim, na década de oitenta a educação popular e não-formal saem da clandestinidade e começam a ser desempenhadas por organizações nãogovernamentais e privadas, bem como a adentrar o ambiente escolar como atividades complementares. E com a Lei de Diretrizes e Bases da Educação Nacional (LBDEN) no Brasil, em 1996, a qual afirma que a educação pode ser desenvolvida em diversos espaços, dando abertura assim, ao debate institucional acerca da educação não-formal, deu abertura também para que, a partir da década de noventa, inicia-se um período que ficou conhecido como o Boom das ONGs, no qual houve um aumento significado do número de ONGs no Brasil, assim como ocorreu em Cabo Verde.

Através de um modelo neoliberal meritocrático, essas organizações da sociedade civil começam a desempenhar um papel intermediador entre o serviço público e as periferias. E é através deste processo de publicização que a educação não-formal começa a se tornar um campo cada vez mais nebuloso.

Como foi visto anteriormente, os processos de aprendizagem pode ocorrer de diversas maneiras, bem como suas propostas, que podem ter um cunho assistencialista, reprodutivo e instrumentalizada garantindo a manutenção do status quo, ou promovendo a educação a partir de um caráter transformador. Mas vale ressaltar que a fronteira entre essas propostas não é 
evidente, ou seja, não é possível considerar se uma proposta é exclusivamente transformadora ou não.

A magnitude e heterogeneidade da educação não-formal torna qualquer generalização um proposição vaga e limitada. Como Jaume Trilla orienta: "a educação não-formal pode ser tão classista, alienante, burocrática, ineficaz, onerosa, obsoleta, manipuladora, estereotipada, uniformizadora etc. como pode ser a formal" (TRILLA, 1985, p.143). Entretanto, a educação formal e não-formal não devem ser analisadas como campos conceituais distintos, pois como tem se notado cada vez mais, a conjugação entre elas abriu novas possibilidades e um possível horizonte para aqueles propõem uma reformulação do sistema de ensino.

\section{A importância da complementaridade dos saberes}

Assim como em Cabo Verde, a diferença entre educação formal e nãoformal no Brasil é rija e nítida por diversos fatores. Enquanto a primeira coincide a escola como espaço do educar regido por normas, regulamentos e currículos, a segunda tem como característica o aprendizado espontâneo e dinâmico de acordo com as peculiaridades socioespaciais e suas carências. Os conteúdos abordados, por exemplo, segundo Trilla (1985) são bem mais amplos e flexíveis do que se evidencia na educação formal, pois esta segue obrigatoriedades, normas e formas metodológicas verbalistas e memorísticas, tornando assim, a aprendizagem um processo limitado à reprodução de conteúdo. Na educação não-formal os conteúdos são selecionados e desenvolvidos de acordo com as necessidades e carências daqueles que se destinam o saber, por isso que neste caso a intencionalidade do educador é muito relevante.

Outro fator importante e diferenciador entre a educação formal e nãoformal é a função que elas cumprem. Como foi visto anteriormente, a formal é regida a partir de uma estrutura limitada e rígida, pois se compõem a um sistema de ensino prescrito. Já a não-formal surge a partir da necessidade de restruturação da sociedade, por isso está em constante 
construção e não possui funções pré-estabelecidas. Das dificuldades do ambiente e do saber escolar se integrarem ao cotidiano dos alunos, por exemplo, a educação não-formal cumpre a função de se estender ou complementar a eles, abrangendo desta forma, grande quantidade de pessoas que não foram incluídas no sistema escolar convencional e/ou que pertencem a grupos sociais marginalizados e desassistidos pelo Estado. Por isso que a educação não-formal possui uma ampla variedade de meios e programas; tem contribuição de diversas áreas do saber; é composta por diferentes bagagens culturais; e prima por funcionalidades diversas, envolvendo-se ao “(...) ao mundo do trabalho, à educação escolar, à educação permanente, à vida cotidiana, à educação especial e a outros aspectos" (GHANEM, 2008, p.2).

Em suma, por mais que existam diferenças conceituais e reveses entre a educação formal e não-formal que refletem no processo de ensinagem e aprendizagem, Trilla (1985) ressalta a necessidade de haver uma colaboração entre Estado e sociedade civil (e não atuação do primeiro sobre a segundo), para que se construa de fato uma educação criadora e democrática. Ou seja, deve-se buscar solucionar as disparidades e promover a integração para que assim, através de uma contribuição mútua e simétrica, os esses dois campos conceituais fomentem um mesmo projeto educacional.

Obstinando esse objetivo, Trilla (1985) chama atenção primeiro a necessidade de reconhecer a transitoriedade, a amplitude e a heterogeneidade do setor não-formal, e segundo, de haver um planejamento do setor não formal e do seus programas específicos, bem como integrá-lo ao planejamento geral dos sistemas educacionais.

Acerca dos programas específicos, Trilla menciona os cinco princípios estalecidos por La Belle (1980):

1) Compreender as necessidades das populações às quais estão dirigidos os programas; 2) Fazê-las participar de sua própria aprendizagem; 3) Facilitar a transferência e aplicação das novas condutas ao meio; 4) Vincular o programa e seus 
componentes ao sistema global, e 5) Dar importância aos incentivos internos e externos. (LA BELLE, 1980, 256)

Então a partir do que foi visto até aqui, a educação não-formal tem um grande potencial para promover uma educação inclusiva, abrindo possibilidade para que as vivências cotidianas e o compartilhamento do saber empírico também sirvam de matéria prima ao ensino. Grande potencial também, porque vai além dos muros das instituições escolares aumentando assim, a oportunidade aos grupos sociais marginalizados de terem acesso a um direito que o Estado se mostrou incapaz de garantir.

Silva (2012), por sua vez, ressalta as contribuições da cultura Hip Hop para esse campo educacional, e por fim, procurarei aprofundar essas questões, pois além do Hip Hop de ser um movimento que age na esfera coletiva, utiliza, através da práxis do pensamento, a arte como um veículo de disputa ideológica e de contraponto às forças hegemônicas das classes dominantes. Sendo assim, seus agentes devem ser destacados não somente como figuras que criticam o status quo e que pleiteiam mudanças estruturas na sociedade, mas também a função educadora que os mesmos cumprem na sociedade.

\section{Novas práticas de ensino: Hip Hop e empoderamento}

Um sistema de ensino público obsoleto e precarizado, baixa adequação dos conteúdos aos contextos (cotidiano) dos alunos, e os métodos de ensinagem restritamente conteudista e reprodutivista explicam bastante a elevada taxa evasão escolar no Brasil. Segundos dados levantados pelos INEP e MEC $^{6}, 12,7 \%$ e $12,1 \%$ dos alunos matriculados na $1^{\circ}$ e $2^{\circ}$ série do ensino médio, respectivamente, deixaram os estudos entre 2014 e 2015. Sendo assim, órgãos governamentais, pesquisadores, educadores, pais e

$6 \quad$ Disponível em: <http://portal.inep.gov.br/artigo/lasset_publisher/B4AQV9zFY7Bv/content/inep-divulga-dados-ineditos-sobre-fluxoescolar-na-educacao-basica/21206>. Acesso em 26 de março de 2019. 
outros atores que participam, direta ou indiretamente, do universo escolar começam a debater e procurar maneiras de solucionar estes problemas.

(...) A escola deixou de ser o único lugar de preparação para a vida ativa, porque a própria vida está se transformando em uma escola de aprendizagem. Dessa realidade não podemos deduzir uma absorção da segunda pela primeira, mas uma coexistência, porque ambas se necessitam. Da primeira, são imprescindíveis os fundamentos básicos, de onde se deve integrar as novas aprendizagens; da segunda recebemos experiências, informação e o estímulo para ir pondo em dia continuamente os conhecimentos e suas aplicações nos âmbitos tradicionalmente estabelecidos. (ROMANS, 2003, p.144).

Nos últimos tempos as experiências com a educação não-formal no meio escolar tem se mostrado produtivas, suscitando assim, importantes reflexões para o processo de reformulação do sistema de ensino, tanto acerca das questão estruturais quanto pedagógicas. Petrus (2003) ressalta que a aula é um espaço de grande potencialidade para realizar debates sobre os conflitos sociais, esporte, política, tabus como sexualidade, uso de drogas, entre outros assuntos. Todavia, antes mesmo de abordas essas questões que afligem o cotidiano da juventude, as escolas não conseguem constatar-se como um ambiente aberto ao debate, ou seja, que proporciona a construção do saber de forma coletiva e compartilhada. Por isso que está sendo cada vez mais recorrente a presença de educadores sociais, sejam eles rappers, poetas, artistas plásticos, recreadores, entre outros para cumprirem essa função ${ }^{7}$.

É comumente considerado o conflito e marginalização social um desafio da educação não formal. Outra característica importante é a diversidade de profissionais que assumem diferentes funções na educação

\footnotetext{
${ }^{7}$ Acerca da reforma do sistema de ensino, vemos aqui mais uma importante questão que a educação não-formal acaba trazendo: a necessidade dos educadores formais adotarem uma nova postura, pois de acordo com as demandas, os professores hoje devem agir como educadores sociais e não como meros comunicadores dos conteúdos curriculares que precisam ser absorvidos pelos alunos.
} 
não-formal. Podem ser skatistas, malabaristas, b-boys, percussionistas, entre outros, pois o que é importante aqui não é a origem da sua formação. Segundo Trilla (1985), as formas de recrutamento são variáveis de acordo com as necessidades e não requer necessariamente status profissionalização, formação, grau ou título acadêmico para que as funções educadoras sejam desempenhadas, encontrando assim, outros termos que se referem e os distinguem dos educadores formais, como oficineiros, arte-educadores, educadores sociais, cuidadores, monitores, educadores de rua, entre outros. Por isso destaco a participação dos rappers e MCs, pois além de serem na sua essência educadores sociais, o rap é um importante instrumento de manifestação artística, política e pessoal principalmente para a juventude pobre, negra e marginalizada, desta forma, destaca-se também como um mecanismo de organização e empoderamento dos mesmos.

A música Pedagoginga do cantor Thiago El Niño, com participação do Sant, traz a tona diversas questões que tornam os ambientes escolares hostis e descartáveis à juventude negra e/ou pobre: má adequação do conteúdo a realidade dos alunos de periferia; narrativas que excluem os negros e ocultam a sua importância na formação histórica do país; racismo estrutural presente no sistema de ensino, entre outros. O próprio nome da música foi escolhido de forma proposital para efetivar essas críticas, pois visa uma educação essencialmente brasileira que relate de fato o que vivemos, e que conte a verdadeira participação histórica dos negros no Brasil, pois a falta disso tem gerado um problema crônico no processo de identificação cultural e racial dos mesmos.

Mano, vou te falar ein, ô lugar que eu odiava Eu não entendia porra nenhuma do que a professora me falava Ela explicava, explicava, querendo que eu criasse um interesse num mundo que não tinha nada haver com o meu.

Não sei se a escola aliena mais do que informa Te revolta ou te conforma com as merdas que o mundo tá 
Nem todo livro, irmão, foi feito pra livrar

Depende da história contada e também de quem vai contar.

Pra mim contaram que o preto não tem vez

E o que que o Hip-Hop fez? Veio e me disse o contrário

A escola sempre reforçou que eu era feio

O Hip-Hop veio e disse: "Tu é bonito pra caralho".

O Hip-Hop me falou de autonomia

Autonomia que a escola nunca me deu

A escola me ensinou a escolher caminhos

Dentro do quadradinho que ela mesmo me prendeu,

Pra superação, tanta humilhação,

Atravessar o oceano para trampar na sua plantação

Café, algodão, cana, escravidão

Alforriaram o nosso corpo, mas deixaram as mentes na prisão ${ }^{8}$.

No capitulo Educação e Libertação: a perspectiva das mulheres negras, Davis (2016) retrata que a emancipação pós-abolição não resultou no acesso a educação e outros direitos sociais para população negra, tendo em vista que o acesso ao conhecimento seria uma grande arma contra a hegemonia branca. Seguindo essa mesma perspectiva, Thiago El Niño explora essas questões no contexto brasileiro ${ }^{9}$ e assim como ressalto outro MC, Hélio Batalha, cabo-verdiano que fez uma música de grande sucesso

\footnotetext{
8 ELNINÕ, Thiago. Pedagoginga. Letra disponível em:

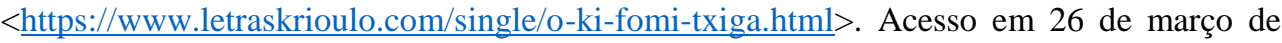
2019.

${ }^{9}$ No videoclipe da música Pedagoginga um menino negro aparece em livrarias e revistarias roubando livros do seu interesse. Leva uma mochila nas costas, demonstrando que o mesmo tem acesso a educação escolar, entretanto é uma forma de salientar o seu desinteresse pelos conteúdos escolares, que mesmo não tendo dinheiro para compra-los, o mesmo decide roubar livros como Hip Hop Genealogia, que conta a história do movimento Hip Hip, e a autobiografia de Malcom X, pois essas obras podem ensinar sobre a realidade e sua identidade a qual o mesmo não encontra narrativas e valores transmitidos na escola.
} 
nomeada $O$ Ki Fomi Txiga ${ }^{10}$ trazendo uma profunda, histórica e complexa reflexão através de uma frase: homis té fomi di palavra ("homens tem fome de palavra"). Ao longo da letra ele narra sobre a violência, fome, desigualdade social e a sobre a falta de oportunidade e de acesso ao conhecimento que, segundo ele, é um dos principais problemas que geram todas essas mazelas sociais a população negra.

Em suma, são essas reflexões que os MCs procuram trazer aos alunos quando se inserem como educadores no ambiente escolar: debater sobre as problemáticas sociais que são tabus no meio escolar; suscitar reflexões e críticas acerca da educação formal; e mostrar como a expressão artística, através da cultura Hip Hop, pode ser também um veículo de organização, consciencialização, empoderamento da juventude. E não obstante, também demostrar o potencial que essa cultura tem de construir um processo educativo emancipatório, que trabalhe as potencialidades e os conhecimentos dos alunos de maneira horizontal, pois o intuito maior não é "passar" conhecimento, mas sim construir o saber coletivamente.

Parece muito coisa, mas o rap tem dois elementos bastante vantajosos: sua linguagem e a forma como ocorre a produção de conhecimento. Diferente da linguagem acadêmica, que as vezes é demasiadamente formal e coloquial, o linguagem dos MCs é totalmente acessível aos alunos pois é formada nas ruas, ou seja, é através das relações sociais estabelecidas no cotidiano que ela se constrói. Já o conhecimento é essencialmente produzido de forma coletiva através do compartilhamento de suas vivencias. Por isso que nas oficinas ministradas, os MCs, diferentes dos professores formais, debatem juntos com os alunos sobre os assuntos que ambos acharem pertinentes. Há, dessa forma, uma horizontalidade e reciprocidade entre os atores no processo de aprendizagem, tanto que é recorrente a figura do educador e educando se inverterem e confundirem ao longo das dinâmicas.

10 BATAlHA, Hélio. O Ki Fomi Txiga. Letra completa disponível em: < https://www.letraskrioulo.com/single/o-ki-fomi-txiga.html>. Acesso em 26 de março de 2019.

Filos. e Educ., Campinas, SP, v.11, n.1, p. 139-155, jan./abr. 2019 - ISSN 1984-9605 
Por fim, acho que todas as contribuições e potencialidades dos MCs como educadores devem ser levadas em conta, assim como dos outros educadores sociais que vêm na educação não-formal uma maneira de transpor as barreiras, tanto físicas quanto teóricas, impostas no sistema de ensino formal. Este que distancia os alunos do acesso a uma perspectiva multicultural do saber, bem como de compreenderem de maneira crítica e autônoma a realidade os quais estão inseridos. Reconheço que os caminhos para que os termos se definhem, e que educação formal e não-formal estejam organicamente englobadas em uma pedagogia social será longo, tendo em vista que muitos educadores não-formais ainda não são conhecidos como tal, e ainda sofrem de estigmas sociais, entretanto, acredito que esse primeiro contato, mesmo que seja entre campos teóricos separados, esta sendo muito importante para evidenciar cada vez mais a obsolescência do nosso sistema de ensino e para suscitar nos alunos, um posicionamento crítico e ativo perante a isso. As ocupações dos alunos ocorrentes em todo o Brasil nos anos de 2016 e de 2017 já demonstraram a força mobilizadora da juventude, que cansados se serem figuras passivas no ambiente escolar, começaram a reivindicar os seus direitos. Deram exemplo e inverteram a lógica, sendo eles os educadores da sociedade brasileira, mostrando o caminho. Agora cabe a nós, como cidadãos, escolher que tipo de educação iremos consentir.

\section{Referências}

CORREIA, Virgílio. Educação e Desenvolvimento. Praia: Colibri. 2007.

DAVIS, Angela. Educação e Libertação: a perspectiva das mulheres negras. In: DAVIS, Angela. Mulheres, Raça e Classe. São Paulo, Boitempo, 2016.

GABINETE DE APOIO ÀS ONG e SECRETARIADO EXECUTIVO DA PLATAFORMA DAS ONG. Educação Popular - o caso de Cabo Verde. Praia: Plataforma das ONG'S de Cabo Verde. 2008. GARCIA, Valéria Aroeira. O papel do social e da Educação Não formal nas discussões e ações educacionais. In: Congresso UNISAL, São Paulo, 2008. 
Disponível em: $\quad<\underline{\text { http://unisal.br/wp- }}$ content/uploads/2013/09/mesa 8 texto valeria.pdf. 2008>. Acesso em 28 de março de 2019.

GHANEM, Elie. In: ARANTES, Valéria Amorim (org). Educação Não Formal: pontos e contrapontos. São Paulo: Summus, 2008.

GOHN, Maria da Glória. Educação não formal e o educador social. Atuação no desenvolvimento de projetos sociais. São Paulo: Cortez, 2010.

LA BELLE, Thomas J. (Ed.). Educación no formal y cambio social en America Latina. México: Nueva Imagen, 1980, p. 256.

PETRUS, Antoni. Novos âmbitos em educação social. In: ROMANS, M., PETRUS, Antoni., TRILLA, Jaume. Profissão: educador social. Porto Alegre: Artmed, 2003, p. 49-111.

ROMANS, Mercè. Formação continuada dos profissionais em educação social. In: ROMANS, Mercè, PETRUS, Antoni, TRILLA, Jaume. Profissão: educador social. Porto Alegre: Artmed, 2003. p. 115-206.

SILVA, Adriano Bueno. Palavra de Mano. Campinas, São Paulo: Editora Página 13, 2012.

TRILLA, Jaume. La educación fuera de la escuela: ámbitos no formales y educación social. - Barcelona: Editorial Ariel, 1996.

TRILLA, Jaume. La educación fuera de la escuela: enseñanza a distancia, por correspondência, por ordenador, radio, vídeo y otros médios no formales. Barcelona: Planeta, 1985.

Submetido em: 15/08/2019

Aceito em: 15/09/2019

Publicado em: 30/10/2019 